\title{
Simulations and Virtual Learning Supporting Clinical Education During the COVID 19 Pandemic
}

This article was published in the following Dove Press journal: Advances in Medical Education and Practice

\section{Shima Tabatabai $(\mathbb{D}$}

Medical Ethics and Law Research Center, Shahid Beheshti University of Medical

Sciences, Tehran, Iran
Correspondence: Shima Tabatabai

Chamran Highway, Velenjak St, Shahid

Beheshti University of Medical Sciences,

Tehran, Iran 19848I3568, Tehran, Iran

Tel +982I 2240561 I

Fax +982I22588016

Email shtabatabai@yahoo.com

\begin{abstract}
Currently, the COVID-19 pandemic has a critical impact on clinical education, and it has resulted in the widespread disruption of clinical assessment. Clinical mentors and students in all the health professions are working within the most troublesome of circumstances in the hospitalbased educational settings. Medical educationists ought to concentrate on the health and the safety of the students and communities. The safety issues have prompted the Ministry of Health to suggest that schools develop action plans for the adoption of available technologies to keep medical education moving forward with high quality, active, and interactive learning for more demanding tomorrow. A key challenge for medical educators is to simulate the clinical encounters at this unprecedented time, and this emphasized the necessity of applying virtual simulation-based educational tools in clinical education. This commentary explores how COVID-19 has challenged medical education. It also has discussed the future implications and potencial challenges of incorporating simulation-based virtual learning technologies into the medical curriculum, for the future of clinical education, and students' or residents' competency evaluation.
\end{abstract}

Keywords: clinical training, COVID-19, challenges, medical education, simulation, virtual learning

\section{Introduction}

Since the perspective of medical education after the pandemic will transform, ${ }^{1}$ it is necessary to engage in futuristic plans to adapt to the impact of COVID-19. The goal of this manuscript is to briefly explain the challenges in clinical training due to COVID 19 and the use of simulation-based technology through virtual education to keep the clinical education on stream throughout the pandemic.

Futuristic plans should have a holistic approach to the ongoing crisis. In this regard, we should initially define the problem and then delineate future horizons. In this commentary, I will briefly outline the potential implications and challenges of integrating virtual simulation technologies into medical education and assessment and how we can overcome those challenges.

\section{COVID-19 Pandemic Impact on Clinical Education}

COVID-19 is an emerging situation, and it continues to spread worldwide, overwhelming the intensive care unit and health system ability. The COVID-19 irruption has influenced each member of the community, not least within the health professions who serve in the front-line of patient care. 
When the World Health Organization declared the pandemic of COVID-19, every country used different strategies, such as epidemiological studies, isolation of diagnosed cases, and school closure, to prevent and to postpone the spread of the disease. ${ }^{2}$

Currently, COVID-19 Pandemic has a critical impact on education system. Meanwhile, it cannot be ignored that clinical mentors and students in all the health professions, working within the most troublesome of circumstances are potential vectors for COVID-19. ${ }^{3}$ In this regard, medical education is shifting to virtual universities. ${ }^{4}$

\section{Virtual Learning in Response to the COVID-19 Outbreak in Iran}

Iran's Ministry of Health and Medical Education (MOHME) suggests that schools develop an action plan for reducing the spread of this extremely contagious disease. In addition, the safety issues have made administrators and educators seeking tools to help them in transferring to virtual learning.

Virtual learning refers to instruction in a learning environment where educators and students separated by time or space or both, and the instructors provide course content through course management applications, multimedia resources, the Internet, videoconferencing, etc. Students receive the content and communicate with the teacher via the same technologies. ${ }^{5}$ Therefore; Virtual learning could consider as a turning point in medical education in Iran due to COVID-19.

In Iran, most medical schools have developed a virtual learning platform. Also, Iran's Virtual University of Medical Sciences (VUMS) has provided authentic resources and educational content to help medical schools all around the country. The National VUMS in partnerships with leading Iranian medical schools is providing what are known as Massive Open Online Courses- MOOCs -through ARMAN systems, accessible at no cost, and without limits on participant numbers or prerequisites. Also, to offer integrated learning experiences for Iranian medical students under the current circumstances, the educational contents deliver through the National Learning Management System entitled NAVID. Like similar learning management systems (LMS), NAVID is helping instructors monitor the learners as well as meeting the individual needs of learners. Some of its main facilities included course content repository, managing users, courses, instructors, facilities, and generate reports, course calendar, learning path, discussion lists. Through this infrastructure, members could offer their contributions, provision of exercises, assigning deadlines to the educational projects and works, assessing the learner's theoretical knowledge, correcting the tests, and providing immediate feedback.

There are several free tools enabling video communications, video and audio conferencing, chats, and webinars for medical educators such as Skype, Zoom, and Google Hangouts Meet. Besides, we can set up a real-time classroom experience that elevates using HD-quality mobile or fixed-camera live and ensures all distance learners can collaborate at an equivalent baseline. ${ }^{4}$

\section{How to Keep the Clinical Education on Track Throughout the COVID-19? Preparing for Future Transformation After the Pandemic}

To maintain high-quality medical education, administrators and medical educationists forced to look for innovative technologies. Moreover, they will need to use emerging technologies that impact on the future way that their institutions will provide medical education.

\section{Determining Probable Challenges}

The challenges for educational institutes are how they could follow the best practices offered by the MOHME to protect students, including social distancing practices, and develop engaged and high-quality clinical education.

In this unique time, the major challenge for medical educators is to simulate clinical encounters. There is an essential question to look at "Do medical education administrators and educators have the tools required to keep the clinical education on track?

Current Virtual learning management systems offer many benefits such as accessibility to educational content from anywhere at any time, asynchronous discussions, and flexibility; however, the challenge is to apply theoretical knowledge to managing the patients.

The latest innovations in flexible educational technologies will change the future of medical education and can facilitate clinical training moving forward with interactive simulation learning. ${ }^{6}$ Computerized Simulation education products for healthcare training environments need massive infrastructures ranging from clinical simulation management software and hardware, design and planning tools, file backup, cloud-based eLearning, as well as an expert team for providing support to counselor education, case developers, and virtual patient training. ${ }^{6-8}$ There are still major barriers to the use of virtual simulation in clinical education. Fidelity and validity issues, cost, and 
expertise issues discussed as barriers for implementing virtual clinical simulation-based education. ${ }^{9,10}$ Virtual universities require careful thinking about how to equip educators or the shift.

\section{Simulation-Based Management Solutions for Virtual Clinical Education}

The simulation-based tools for healthcare training would be desperately required by health and medical education programs to support continual clinical education and assessment.

Computerized simulation education products and virtual simulation-based solutions provide the necessary tools to provide benchmarking and best practice insights to medical sciences students, better preparing them for real-world medical practice. ${ }^{9-12}$ some medical simulation products are also available and ready for immediate deployment on the medical education LMS and cloud-based platform. ${ }^{13}$

Moreover, in recent years, medical schools are using virtual patient simulations in the education of health care professionals. England's health education systems and Oxford University Hospitals are using virtual simulationbased tools in undergraduate and postgraduate medical education. $^{13}$

\section{Clinical Skills Assessment}

Clinical skills assessment is one of the main parts of clinical education to assess practical qualifications. ${ }^{14}$ Iran's board exam for evaluation of medical students and residents' clinical qualifications is an Objective Structured Clinical Examination (OSCE). This high-stakes performance assessment method requires experienced human resources, accurate planning, facilities, and reliable evaluation tools.

Protecting the safety of all participants, minimizing risk and maintaining defensibility to key stakeholders whilst ensuring the validity, and reliability of high-stakes performance assessments are other challenges. ${ }^{7}$ The future of clinical education depends on the integration of virtual simulation-based technologies and virtual clinical experience into the medical curriculum. As virtual simulation will continue to expand 11-12, some educational institutes are investigating Virtual simulation application in objective structured clinical examinations (OSCEs), as a method of increasing the objectivity of their assessment processes. ${ }^{15}$

Simulation-based educational technologies keep the clinical education on stream in the following ways:
- The simulation platform's optional course module allows learners to move to a virtual environment.

- The Simulation-based platform changes traditionally time-consuming manual processes to create an integrated approach that improves clinical outcomes, saves time, and delivers electronic-based content. Schedule simulated meetings, facilitate distance learning with video conferencing, and review the clinical decision-making with learners. ${ }^{9,10}$

- It allows the learners to access the clinical scenarios via the computer or mobile device. The dashboard improves educational task flows and customizes remote learning parameters specific to the program requirements regardless of the learners' location.6,10

- By Simulation-based platform, clinical educators could conduct high-impact cased-based simulated training scenarios online and Run Live, virtual OSCEs from anywhere.12,14

- Simulation-based Virtual OSCE offers the perfect cloud-based platform to lead standardized patient (SP) confronts in a completely virtual, video-enabled environment to address all clinical education needs. ${ }^{13,14}$

- Simulation-based Virtual OSCE facilitates core learning for clinical decision making in distance learning platforms, as well as the emerging demand to transform clinical practice into telemedicine forms. ${ }^{14}$

\section{Conclusion}

Considering the benefits of simulation-based healthcare environments, Medical school administrators should invest in simulation-based educational management technologies and products to keep the clinical education and competency assessment on track throughout the COVID-19 pandemic.

\section{Disclosure}

There is no conflicts of interest in this work.

\section{References}

1. Tabatabai S. Necessity of designing a national model of foresight-based policy-making in medical education. Strides Dev Med Educ. 2017;14(3):e67446. doi:10.5812/sdme.67446.

2. WHO. Available from: https://www.who.int/dg/speeches/detail/whodirectorgeneral-s-remarks-at-the-mediabriefing- on- 2019-ncov-on-11february-2020.

3. Ahmed H, Allaf M, Elghazaly H. COVID-19 and medical education. Lancet. 2020;20(7):777-778. doi:10.1016/S1473-3099(20)30226-7.

4. Covid-19 reviving need explore online teaching and learning opportunities [Internet]; 2011.Available from: https://epale.ec.europa.eu/en/ blog/covid-19-reviving-need-explore-online-teaching-andlearningopportunities\#epale-comments-btn. 
5. Alves P, Miranda L, Morais C. The influence of virtual learning environments in students' performance. Univ J Educ Res. 2017;5 (3):517-527. doi:10.13189/ujer.2017.050325

6. Tabatabai S. Effects of physician- patient electronic communications on the quality of care. IJRQE-Healthcare. 2013;3:56-64. doi:10.4018/ ijrqeh.2013040105

7. Fioccola GB, Sommese R, Tufano I, Canonico R, Ventre G. "Polluino: an efficient cloud-based management of IoT devices for air quality monitoring," 2016 IEEE 2nd international forum on research and technologies for society and industry leveraging a better tomorrow (RTSI). Bologna. 2016;1-6.

8. Chan KS, Zary N. Applications and challenges of implementing artificial intelligence in medical education: integrative review. JMIR Med Educ. 2019;5(1):e13930. doi:10.2196/13930

9. Day RS. Challenges of biological realism and validation in simulation-based medical education. Artis Intell Med. 2006;38 (1):47-66. doi:10.1016/j.artmed.2006.01.001
10. Ronsen KR. The history of medical simulation. J Crit Care. 2008;23 (2):157-166. doi:10.1016/j.jcrc.2007.12.004

11. Nestel D, Bearman M. Simulated Patient Methodology: Theory, Evidence, and Practice. Chichester: Wiley- Blackwell; 2015.

12. Tabatabai S, Javadi MA. Ophthalmic education and ophthalmologists growth trends in Iran (1979-2016). J Ophthalmic Vis Res. 2019;14 (2):185-194. doi:10.4103/jovr.jovr_24_18

13. McGaghie WC, Issenberg SB, Petrusa ER, Scalese RJ. A critical review of simulation-based medical education research: 2003-2009. Med Educ. 2010;44(1):50-63. doi:10.1111/j.1365-2923.2009.03547.x

14. Tabatabai S, Simforoosh N, Ziaee AM. The crucial necessity of designing competency based curriculums for post graduate medical education in Iran. Strid Dev Med Educ. 2016;13(1):104-106.

15. Boursicot K, Kemp S, Ong T, et al. Conducting a high-stakes OSCE in a COVID-19 environment. MedEdPublish. 2020;9(1):54. doi:10.15694/mep.2020.000054.1

\section{Publish your work in this journal}

Advances in Medical Education and Practice is an international, peerreviewed, open access journal that aims to present and publish research on Medical Education covering medical, dental, nursing and allied health care professional education. The journal covers undergraduate education, postgraduate training and continuing medical education including emerging trends and innovative models linking education, research, and health care services. The manuscript management system is completely online and includes a very quick and fair peer-review system. Visit http://www.dovepress.com/testimonials.php to read real quotes from published authors. 